\title{
Representações sociais sobre o cuidar do doente mental no domicílio
}

\author{
Social representations about the homecare of the mental sick person \\ Representaciones sociales del cuidar del enfermo mental en el hogar
}

\section{Marcela Bruno de Carvalho Silva', Dora Sadigursky"}

'Faculdade NOVAFAPI. Teresina, PI

"Universide Federal da Bahia. Salvador, BA

Submissão: 19/03/2008

Aprovação: 3 1/07/2008

\section{RESUMO}

O presente estudo tem como objetivos apreender e analisar as representações sociais construídas pela família sobre o cuidar do doente mental no domicílio e orientado pela Teoria das Representações Sociais. O campo de estudo foi o Centro de Saúde Mental Professor Aristedes Novis, em Salvador-BA, os sujeitos da pesquisa foram 100 familiares Que cuidam de doentes mentais em casa. Os dados pela Análise de Conteúdo categorial temática de Bardind e pela da Análise Fatorial de Correspondência, através do software Tri-DeuxMots. A análise de conteúdo apreendeu as representações sociais do cuidar do doente mental construídas pelas famílias. A Análise Fatorial de Correspondência complementou com as palavras: atenção, dor, adoece, agressão e deseQulíbrio.

Descritores: Transtornos mentais; Família; Cuidadores.

\section{ABSTRACT}

The object of this study is the social representations built by family on taking care of the mental patient at home and it brings as its goals: to apprehend the social representations built by the family on taking care of the mental patient at home, to analyze the aspects that influence taking care of them. The collection were analyzed through Correspondence Factorial Analysis, by the software Tri-DeuxMots. From these analysis apprehend the social representations built by the family on taking care of the mental patient at home. In the factorial analysis of correspondence, through the stimuli mental disease and taking care of a mental patient, words like attention, pain, get sick, aggression, unbalance.

Descriptors: Mental disorders; Family; Caregivers.

\section{RESUMEN}

El objecto de este estudio es las representaciones sociales construidas por la familia en el cuidar del paciente mental en el hogar y trae como sus metas: aprehender las representaciones sociales construidas por la familia en el cuidar del paciente mental en el hogar $y$ analizar los aspectos que influencian el cuidar de ellos. Es una investigación dirigida por la teoría de las representaciones sociales. Los dados fueran analizadas con análisis factorial de la correspondencia, por el software Tri-Deux-Mots. Por medio de la análisis factorial de la correspondencia e por medio de las palabras estimulo: paciente mental e el cuidar del paciente mental, fueran apreendidos los seguintes significados: atención, dolor, enferma, agresión, desequilibrio.

Descriptores: Transtornos mentales; Família; Cuidadores. 


\section{CONSIDERAÇÕES INICIAIS}

No Brasil, as políticas de saúde mental têm sua Qualidade Questionada, constantemente, pelos profissionais, familiares e usuários, principalmente no Que se refere à forma de tratamento e de cuidados prestados. Observa-se, ainda, na atualidade, a violação dos direitos humanos e de cidadania, visto Que, muitos pacientes portadores de enfermidade mental encontram-se condenados ao isolamento e aos maus tratos dentro dos Hospitais Psiquiátricos, além de sofrer, constantemente, preconceitos e discriminação por parte das comunidades nas Quais estão inseridos.

Entretanto, de acordo com a história da psiquiatria, ocorreram inúmeros movimentos na Europa, entre os anos 1950 e 1960 , Que visavam combater os internamentos hospitalares e o modelo hospitalocêntrico. Estes movimentos serviram como influência ao processo de desinstitucionalização psieuiátrica no mundo e, também, no Brasil, com a reforma psieuiátrica brasileira ${ }^{(1)}$.

A reforma psieuiátrica brasileira foi baseada no Decreto - Lei de Paulo Delgado, em 1989, e buscava, em especial, desestimular a internação de doentes mentais, visando assim a desinstitucionalização, com o argumento de Que os Hospitais Psiquiátricos não exerciam a função terapêutica adequada e, devido a isso, deveriam ser utilizados, apenas, como último recurso de tratamento. Atualmente, o Brasil dispõe da lei 10216 (06/04/2001), Que discorre sobre a proteção e os direitos das pessoas portadoras de transtornos mentais e redireciona o modelo assistencial em saúde mental ${ }^{(2)}$. Com a implantação da política de desinstitucionalização e com o processo de ressocialização do doente mental, a família passou a ter importante papel na assistência psiQuiátrica. O convívio contínuo com paciente portador de transtorno mental acaba por desestruturar o grupo familiar no Que diz respeito à vida social, ao lazer, a relação com os outros membros da família, a rotina doméstica, aos problemas financeiros, entre outros fatores Que interferem no cotidiano dos familiares ${ }^{(3)}$.

As observações Que motivaram esta pesquisa foram feitas dentro das instituições psiquiátricas, onde os pacientes eram internados e, na grande maioria das vezes, abandonados pela família Que, apesar da tentativa de conscientização por parte da equipe de saúde, criava uma resistência muito grande para o convívio com o doente mental dentro de casa e, geralmente, voltava a interná-lo, logo em seguida, em outras instituições.

Portanto, a situação-problema Que se reflete neste estudo relaciona-se ao despreparo das famílias de portadores de transtornos mentais para cuidar dos doentes mentais em casa, ressaltando-se Que, a família é parte fundamental no processo de ressocialização deste paciente e que, devido a isso, é essencial analisar, os motivos Que levam as famílias ao medo e à não aceitação da presença do portador de transtorno mental no convívio diário.

Visando analisar tais motivos, este estudo baseia-se na Teoria das Representações Sociais ${ }^{(4)}$ Que, vai além dos fatos de instituição, da coleta das ideologias e dos documentos, interessa-se por crenças e pelo modesto cotidiano do pensamento e do sentimento. Assim, o Que esta teoria atinge não é algo excepcional ou sistemático, é antes a banalidade, e o Que não nos chama a atenção, é o fato anônimo do Qual ninguém se detém.

A representação dada pelo sujeito de uma pesquisa sobre um determinado objeto, deve ser efetivamente praticada e não apenas suposta, isto é, deve ser detectado em comportamentos e comunicações Que de fato ocorreram sistematicamente. Assim, o fenômeno social do cuidar de um doente mental em domicilio envolve uma serie de representações Que estão disseminadas na cultura, nas instituições, nas práticas sociais, nas comunicações interpessoais e de massa e, também, nos pensamentos individuais ${ }^{(5)}$.

Deste modo, pode-se afirmar Que tal convivência é um fenômeno social e a partir desta constatação, delimitou-se como sujeitos deste estudo, a família do doente mental desistitucionalizado, devido ao fato de ser esta a população Que vivencia tal fenômeno. Sendo assim, para responder aos Questionamentos sobre o convívio dos familiares com aqueles Que são mentalmente incapacitados, determinou-se como objeto de estudo as representações sociais construídas pelas famílias sobre o cuidar do doente mental no domicílio.

Partindo então do interesse de estudar o cuidar do doente mental pela família sobre a ótica das representações sociais, alguns Questionamentos são relevantes: 1) Quais as representações sociais do cuidar do doente mental no domicílio construídas pela família? 2) Quais são os aspectos capazes de influenciar esse cuidar?

Buscando solucionar tais Questionamentos, os objetivos deste estudo são: Apreender e analisar as representações sociais construídas pela família sobre o cuidar do doente mental no domicílio.

É importante colocar Que a utilização das representações sociais para nortear essa pesquisa pôde trazer novas contribuições em relação ao cuidado prestado pelas famílias ao doente mental, assim como ao suporte Que esta família necessita receber, para fornecer uma assistência mais adeQuada a este paciente.

\section{CAMINHO METODOLÓGICO}

Trata-se de um estudo exploratório Que aborda aspectos Quantitativos e Qualitativos em Que se buscou apreender e analisar as representações sociais do cuidar do doente mental em domicilio relacionadas ao objeto de estudo, tendo como ponto de partida o senso comum das famílias.

O estudo foi desenvolvido no Centro de Saúde Mental Profo Aristides Novis, situado no bairro de Engenho Velho de Brotas na cidade de Salvador, capital da Bahia. Esse Centro é composto pelo Centro de Atenção Psicossocial (CAPS) e pelo Serviço de Atendimento Ambulatorial Que faz o acompanhamento e o controle mensal dos pacientes Que buscam o serviço.

Fizeram parte desta investigação 100 sujeitos selecionados, no ambulatório do Centro de Saúde Mental, Que foram submetidos ao Teste de Associação Livre de Palavras (TALP). Os critérios para a escolha dos sujeitos desta pesquisa foram os seguintes: ser familiar de um portador de transtorno mental, possuir um doente mental fora da instituição, ou seja, Que receba os cuidados em casa, ser familiar de um usuário do Centro de Saúde Mental Profo Aristides Novis, aceitar participar do estudo e estar em condições de ser entrevistado.

Dentre os 100 sujeitos Que responderam ao teste de associação livre de palavras, foram convocados 3 I sujeitos para responderam à entrevista semi-estruturada, esta seleção ocorreu de acordo com a disponibilidade destes familiares em responder aos Questionamentos da entrevista. 
Todos os sujeitos Que participaram deste estudo, receberam esclarecimento da importância e da relevância da pesquisa e, após aceitação verbal dos mesmos, culminou a assinatura do Termo de Consentimento Livre e Esclarecido, Que obedece aos aspectos éticos e legais conforme o Comitê de Ética em pesquisa da Maternidade Climério de Oliveira, acordado com os requisitos da Resolução CNS 196/96, Que trata das diretrizes e normas de pesquisa envolvendo seres humanos, como por exemplo, a garantia do sigilo e a liberdade da recusa ou retirada do seu consentimento em Qualquer fase da pesquisa ${ }^{(6)}$. A entrevista foi composta do seguinte roteiro: primeira parte com dados sociodemográficos definidores do perfil dos sujeitos: idade, sexo, grau de parentesco e escolaridade e, a segunda parte com as Questões: 1) O Que é para você cuidar de um doente mental em casa? 2) Quais as implicações para a vida familiar, ter Que cuidar de um doente mental em casa?

Para analisar os dados foram utilizadas as técnicas de Análise de Conteúdo Categorial Temática(7), no caso das entrevistas semiestruturadas, e a Técnica de Análise Fatorial de Correspondência (ACF), nos testes de associação livre de palavras, através da utilização do software Tri-Deux-Mots ${ }^{(8)}$.

A Análise de Conteúdo Categorial Temática ${ }^{(7)}$ é realizada por processos de desmembramento do texto em unidades, em categorias segundo reagrupamento analógico. Entre os vários tipos de categorização a análise temática é rápida e eficaz em discursos diretos e simples.

$\mathrm{Na}$ análise de conteúdo deste estudo, inicialmente, realizou-se uma leitura flutuante do texto Que permitiu fazer a constituição do corpus, isto é, selecionar o Que material a ser analisado pelo pesquisador de acordo com os objetivos da pesquisa.

Após esta etapa houve a seleção das unidades de análise através do recorte e da codificação do corpus. Em seguida, foi feita uma operação de classificação de elementos constitutivos de um conjunto (unidades de registro), por diferenciação e por agrupamento segundo o gênero, com os critérios anteriormente definidos. Tais unidades foram agrupadas semanticamente, para formação das subcategorias e, em seguida, das categorias.

A Técnica de Análise Fatorial de Correspondência (AFC), é outra técnica de análise de dados, utilizada neste estudo ${ }^{(9)}$, permite agrupar os campos semânticos e aumentar, consideravelmente, os dados amostrais para pesquisas Qualitativas inacessíveis, anteriormente, além de assumir um papel cada vez mais importante no estudo das ciências sociais.

Não foram encontradas dificuldades na abordagem dos sujeitos, estes antes de iniciarem o teste de associação livre de palavras passaram por um "treinamento" de como responder ao teste. Este treinamento consistia em dar um exemplo de uma palavra do cotidiano do sujeito e pedir que este dissesse as 5 primeiras palavras Que ele associava ao estímulo dado. Ex: Dava-se como estímulo a palavra "Futebol" o sujeito logo respondia: "Bola, Trave, Goleiro, Jogo, Juiz". O treinamento era repetido mais uma vez com outra palavra cotidiana e, em seguida, era realizado o teste com os estímulos relevantes para a pesQuisa: doença mental e cuidar do doente mental.

Após obtenção das palavras emitidas pelos sujeitos, foram criados dicionários de vocábulos com todas elas e agrupadas por similaridade semântica. Posteriormente, foram dispostas em linhas horizontais, codificadas e interligadas a numerais diferentes, representantes dos estímulos indutores ( 1 - doença mental e 2cuidar do doente mental). Após a organização e o preparo do banco de dados, as informações foram processadas no software Tri-Deux Mots $^{(8)}$, Que é indicado para a avaliação, de Questões abertas e fechadas, sendo interpretado por análise fatorial de correspondência (AFC). A análise fatorial de correspondência é importante no dimensionamento do campo das representações sociais ${ }^{(10)}$.

\section{ANÁLISE E DISCUSSÃO DOS DADOS}

Através da entrevista semi-estruturada é possível a apreensão das representações sociais do cuidar do doente mental em domicílio na ótica da família e, com o teste de associação livre de palavras pode-se, graficamente, através da correlação entre as variáveis fixas e variáveis de opinião, obter a objetivação feita pelos sujeitos da pesquisa em relação ao fenômeno estudado.

A Teoria das Representações Sociais é uma aliada importante para o diagnóstico dos aspectos psicossociais Que envolvem o convívio do doente mental com sua família, dentro de casa, aspectos estes Que ancoraram-se em fatores culturais, sociais e até mesmo nas crenças destas famílias, além de determinarem a conduta a ser adotada por parte dos familiares no cuidado ao portador de transtorno mental.

No processo de categorização surgiram 344 unidades de registro (ou unidades de análise). Estas unidades agrupadas formaram um conjunto de categorias e subcategorias agrupadas formaram , todas construídas a partir do material das entrevistas, foram validadas por professores Que trabalham com o mesmo referencial teóricometodológico e serão descritas a seguir. No agrupamento das categorias temáticas e, das suas respectivas subcategorias, foram considerados durante o processo de análise, suas inter-relações, seus consensos e divergências e até mesmo a relação das categorias entre si e a convergência com os resultados obtidos através da Análise Fatorial de Correspondência.

Categoria A - Descrições das manifestações sobre o cuidar do doente mental em casa.

Esta categoria está subdividida em 224 unidades de registro distribuídas nas Quatro subcategorias referentes ao relacionamento do doente mental com a família, aos aspectos socioeconômicos Que simbolizam a dificuldade em manter um doente mental em casa, aos fatores psicossociais e às informações explicativas ou justificadoras Que os sujeitos expressaram através de opiniões de caráter afetivo e cognitivo sobre o fenômeno do cuidar do doente mental.

A subcategoria Que abrange as manifestações relacionais do cuidar refere-se às agressões físicas e psicológicas relatadas pelos familiares bem como, aos sentimentos como medo, receio e desconfiança por parte da família:

[...Jeu sou Quem ele agride mais, o meu filho com esse problema de ouvir vozes tenho Que ter cuidado, porque a primeira pessoa Que ele desconhece sou eu[...] lquando ele acorda a noite, ele é de lua, fica muito agressivo já puxou até faca pra mim[...].

Manifesta ainda, a falta de paciência por parte da família para 
lidar com o doente mental e a relação com os doentes mentais, Que é, muitas vezes, um fator de incomodo e de empecilho para uma vida familiar harmoniosa:

[... Jquando ele não dorme ele também não me deixa dormir[... lquando ele não dorme ele mexe em tudo dentro de casa pra me chamar a atenção e não me deixar dormir[...]as vezes ele me tira da paciêncial...].

A convivência com alguém Que, por muitas vezes, fica acordado durante uma noite inteira conversando sozinho ou falando coisas Que só faz sentido para ele mesmo, contribui para Que o clima dentro de casa se torne alterado e pesado ${ }^{(11)}$.

Nas manifestações socioeconômicas destaca-se a falta de recursos financeiros Que permitam aos familiares prestarem uma assistência adequada aos doentes mentais:

[...]sem dinheiro não se tem nada, o sacrifício na família cresceu|... Jesta muito difícil as condições de vida dela e eu não tenho como ajudar[... Juma casa onde todo mundo é desempregado, onde não temos plano de saúde é muito difícil[...].

É ônus muito pesado para as famílias, principalmente as de baixa renda, a manutenção e o sustento de um membro improdutivo em casa ${ }^{(2)}$

Nas manifestações psicossociais existem relatos de sentimentos contraditórios pois esta subcategoria encontra-se intimamente ligada tanto a sentimentos de medo, tristeza e preocupação, Quanto a sentimentos Que refletem paciência, carinho, amor e compreensão:

[...]é muito triste, a gente fica sozinha, é Que tem a responsabilidade por ele[...Jé muita preocupação, muita luta[...]é da carinho, amor, compreensão/...Ja gente tem Que ter segurançal... Jé mostrar nosso amor, amor e cuidado ele mesmo vê o cuidado, o amor e a paciência Que eu tenho com ele[...].

Quando a família possui entre seus membros um portador de transtorno mental, esta fica caracterizada por sintomas típicos de ansiedade, conflito interior e sentimentos como tristeza e angustia ${ }^{(13)}$.

Por outro lado, no cotidiano do cuidar de um doente mental é necessário Que haja maleabilidade e flexibilidade por parte dos cuidadores. No cotidiano do cuidar é necessário Que a família consiga controlar suas próprias expressões de humor para poder apreender as possíveis reações dos doentes mentais, e conseguir lidar com elas ${ }^{(14)}$.

Categoria B - Implicações relacionadas ao cuidar do doente mental em casa.

A Categoria B está subdividida em 54 unidades de registro distribuídas em três subcategorias Que denotam as implicações do cuidar de um doente mental para a família. As subcategorias referem-se à desestabilização familiar sofrida pela família decorrente de divórcios, desentendimentos e Queda na renda familiar, à restrição de liberdade de Quem cuida por necessidade de constante acompanhamento do doente mental e ao desgaste físico/psíuuico sofrido muitas vezes pela grande maioria dos sujeitos da peseuisa.
Na subcategoria das implicações relativas à desestabilização familiar destacaram-se relatos Que faziam referências a situações de desarranjo familiar e de casais Que não suportando o convívio inclinam-se para a separação.

[...]ele era o cabeça da casa, a pessoa mais centrada, vai fazer três anos que ele esta doente, ai desestabiliza a casa toda[...]

[... Jatrapalha tudo, atrapalha a vida dele e desestrutura toda a família[... Ileueria me separar, eu falei com o irmão dela essa semana que acho que vou me separar porQue não vai dar certo não|...]

Este tipo de conflito predispõe ao desequilíbrio das relações familiares, levando à ruptura da comunicação, à regressão e à desintegração da família(13).

Nas implicações Que refletem a restrição de liberdade de Quem cuida, os relatos denotam as Queixas dos familiares sobre a falta de liberdade de ir e vir.

[...] a gente se ocupa demais, não tem tempo pra se divertir, o dia a dia da gente é só cuidar do doente, até para sair é difícil[...]

[...Ise eu Quiser viajar ele empata um pouco, isso me incomoda porque sempre tem que ter uma pessoa com ele[...]

[...Inão posso trabalhar porQue não tem Quem fieue com ele, tem sempre Que haver alguém pra observar ela, para ela não estar na rua, porQue a gente nunca sabe[...]

Fazem parte das rotinas familiares as atividades de ir e vir, portanto, sendo o doente mental dependente da família para realizar sua própria rotina, o familiar Que cuida acaba por assumir as atividades do doente interrompendo, com isso, suas próprias atividades.

Na última subcategoria Que reflete as implicações sobre o cuidar do doente mental no domicílio destacam-se falas Que demonstram o desgaste físico/psípuico de Quem cuida.

[...J se ele fica Quinze dias, ou três semanas comigo dentro de casa eu fico mal também/.../Quase sempre Quando ele sai de casa pra se internar ele me deixa acamada[...]/to passando a tomar chazinho, suco de maracujá, tudo pra acalmar[...]

Muitas vezes, a convivência estressante com portadores de transtornos mentais resulta em doenças para a família Que cuida(11).

\section{Campo de representação ou imagem.}

Conforme já mencionado na metodologia os dados obtidos no Teste de Associação Livre de Palavras foram processados no software Tri-Deux Mots e deram origem a 752 palavras em respostas aos estímulos/indutores doença mental e cuidar do doente mental sendo Que destas, 94 constituiu-se de palavras com significados diferentes.

No eixo horizontal o Fator $\mathrm{I}(\mathrm{Fl})$ as modalidades são apresentadas na cor laranja, no eixo vertical Fator 2 (F2) as evocações são destacadas na cor azul e para as modalidades Que contribuíram compara os dois fatores Fl e F2 foi atribuída da cor verde. Destaca-se ainda, no final de cada palavra evocada o numero 
Que codifica para Qual estimulo ela contribuiu com maior freeüência, ou seja, o número I para doença mental e o número 2 para cuidar do doente mental.

O procedimento analítico se deu seguindo a ordem estabelecida pelo gráfico, iniciando-se no lado esquerdo (negativo) do FI (eixo laranja) e lado direito (positivo) deste mesmo fator e em seguidas as palavras Que se encontram no lado superior (positivo) do F2 (eixo azul) e terminando no seu lado inferior (negativo).

\section{Fator I - Lado Esquerdo}

No lado esQuerdo do gráfico do fator FI (eixo horizontal laranja), encontram-se um conjunto de representações sociais sobre doença mental e cuidar do doente mental, elaboradas pelos pais com idade superior a 50 anos, isto porQue esta categoria de sujeitos foi a Que mais contribuiu para as representações sociais do cuidar do doente mental em casa.

Estes sujeitos objetivam doença mental, com modalidades descritas como: ruim, agressão, Deus, despesas e dor. Através dessas modalidades os pais relacionam a doença mental a busca na fé em Deus utilizado-a como suporte e apoio para o enfrentamento das dificuldades encontradas no convívio com o doente mental. Estes achados complementam os das entrevistas analisadas nas Quais, os familiares se apóiam nas crenças religiosas, além de referirem a doença mental como algo negativo Que promove sofrimento, tristeza e dor além de sofrem agressões dos seus doentes mentais. Uma outra variável referida nas evocações e relatadas nas entrevistas, no Que diz respeito à doença mental, destaca-se as dificuldades financeiras vivenciadas no cotidiano dessas famílias.

Em relação ao cuidar do doente mental, os pais objetivaram duas variáveis de opinião com conteúdos negativos, Quais sejam: dificuldade e agressão. Estas representações deixam claro Que os familiares têm dificuldade em lidar com o doente mental dentro de casa e Que por serem constantemente agredidos associam o cuidar às agressões sofridas, objetivando Que cuidar de um doente mental é sinônimo de ser agredido.Estes resultados corroboram os achados feitos anteriormente ${ }^{(1)}$ ao afirmarem Que as manifestações agressivas são as principais causas da sobrecarga familiar.

\section{Fator 1- Lado Direito}

O lado direito do gráfico do mesmo fator FI, na cor laranja, observa-se a delimitação do agrupamento das representações sociais sobre os mesmos estímulos doença mental e cuidar do doente mental, construídas por familiares do sexo masculino, Que cuidam de doentes mentais em casa.

Para o estímulo doença mental, os cuidadores do sexo masculino evocaram as modalidades: adoecer, cuidar, acompanhar e atenção. Evidencia-se Que na concepção dos sujeitos a doença mental traz a imagem de ser uma doença e, Que por ter status de doença, justifica-se a necessidade de cuidados específicos, acompanhamento e atenção, por parte de Quem cuida. Estas objetivações, portanto, atendem à função justificadora das representações sociais.

No caso do estímulo, cuidar do doente mental, é manifestado pelos cuidadores um campo representacional correspondente a médico e acompanhar, demonstrando que para os mesmos cuidar de um paciente Que tem transtorno psíquico significa acompanhálo ao médico. Para muitos familiares, a busca por atendimento médico é a única maneira de prestar assistência de Qualidade ao doente mental a Qual contribui para suprir as necessidades do doente e da família ${ }^{(15)}$.

\section{Fator 2- Lado Superior}

No lado superior do gráfico, eixo F2 (vertical azul), as imagens representadas pelos estímulos doença mental e cuidar de um doente mental, tiveram uma maior contribuição de evocações, por parte dos filhos dos doentes mentais.

No Que se refere ao estímulo doença mental os filhos, sujeitos sociais pesquisados, contribuíram neste fator com as evocações adoece, dor, depressão e dificuldade. A modalidade adoece evidencia Que a doença mental é vista pelos sujeitos como um distúrbio, Que para a família se revela com muita dificuldade o cuidar diário e Que provoca sofrimento, expressados pelos sentimentos de dor e depressão. Estas representações corroboram com os achados anteriormente identificados nas entrevistas, onde existem relatos Que demonstram, sentimentos de angustia vivenciados cotidianamente pelos familiares de doentes mentais.

Em relação ao estímulo anamente vivenciados ntivicado nas cuidar do doente mental, os filhos objetivaram o cuidar com uma única modalidade: atenção. Essa palavra surgiu na elaboração do dicionário, Que deu-se através do agrupamento de palavras com similaridade semântica destacadas entre as evocações horários de medicação e responsabilidades. Através dessas modalidades e do conteúdo das entrevistas, os sujeitos reconhecem o cuidar de um portador de transtorno mental, como algo Que reQuer atenção com o tratamento disponibilizando a alimentação e o remédio na hora certa. Ao evocarem a modalidade atenção os sujeitos revelam por outro lado, a falta de confiança, o medo e a insegurança Que vivenciam ao ter um portador de transtorno mental em casa, exigindo atenção permanente à sua movimentação e às suas atitudes, tendo em vista ao reconhecimento por parte dos familiares, da imprevisibilidade das reações Que os portadores de doença mental apresentam.

\section{Fator 2- Lado Inferior}

No eixo inferior (fator 2) vertical azul, estão representadas as imagens dos estímulos doença mental e cuidar do doente mental, pelos sujeitos denominados como outros (os Quais estão inclusos: avós, primos(as), tios(as), cunhados(as), genros, noras, sogros(as), vizinhos, entre outros) Que encontram-se entre 3 I e 50 anos.

Neste sentido, para o estímulo doença mental foram evocadas as modalidades: atenção, dependência, desconhecimento, desequilíbrio, esquizofrenia, doido. Considera-se, portanto, que na visão destes sujeitos, o transtorno mental é uma doença Que necessita de atenção por parte de Quem convive com ela, Que provoca dependência do doente mental, sendo este, muitas vezes, impossibilitado de realizar tarefas simples do seu cotidiano, tarefas estas Que incluem a higiene pessoal, a alimentação e, seu próprio deslocamento. Outra modalidade citada pelos sujeitos é o desconhecimento da doença, no Que se refere às suas causas, suas conseqüências e, em especial, no Que se refere às reações dos doentes no convívio com os familiares no domicílio. Ao referirem as variáveis, desequilíbrio, esquizofrenia e doido ancoram a doença mental nos aspectos culturais, como uma forma de conhecimento socioculturalmente elaborada e partilhada, construída pelos sujeitos sociais, ao reconheceram a doença mental como enfermidade Que promove desequilíbrio no doente e o deixa doido e esquizofrênico. 


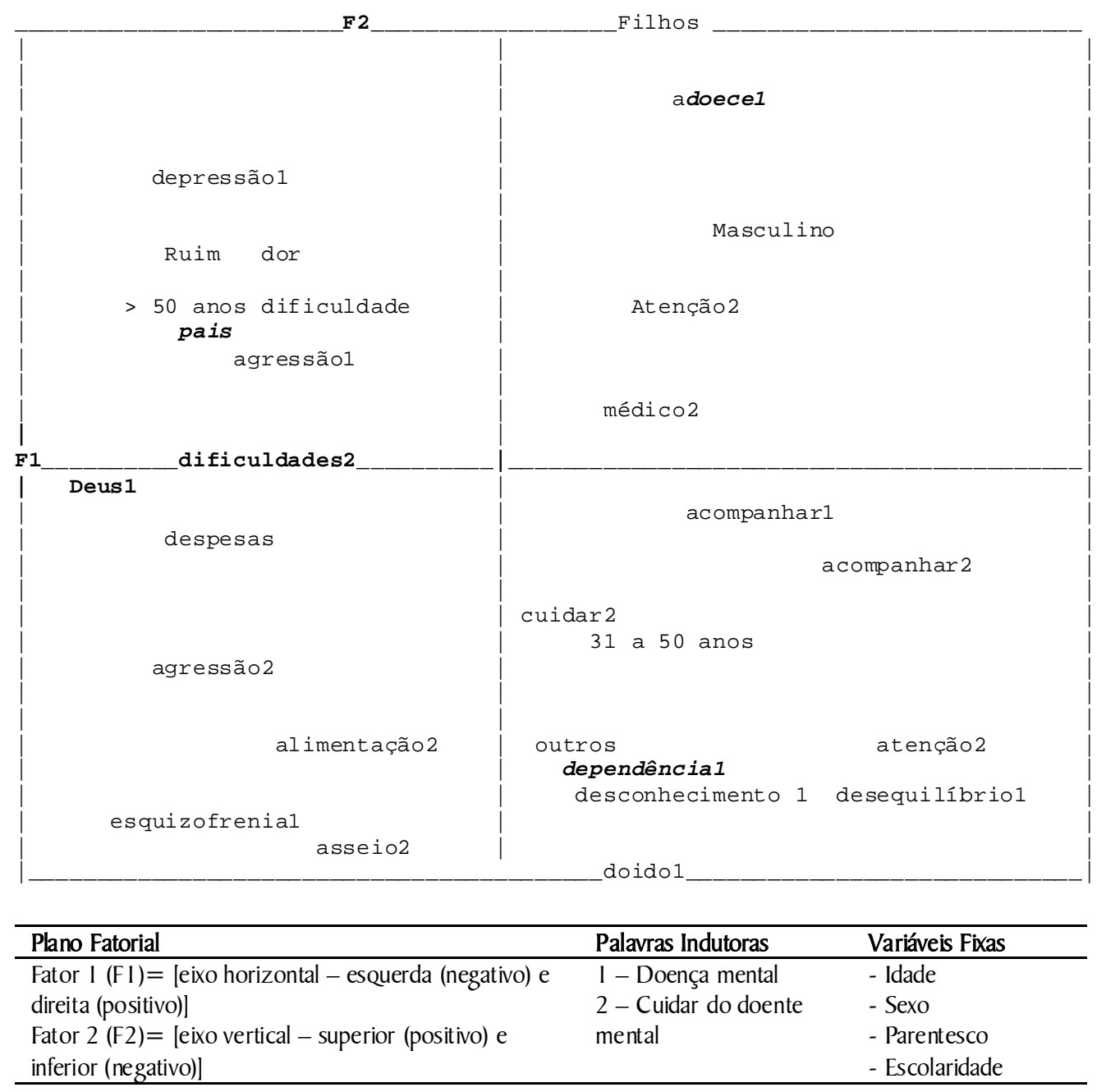

Gráfico 1. Representação do plano fatorial sobre cuidar do doente mental no domicílio pela família.

Para o estímulo cuidar do doente mental foram evocadas as palavras cuidar, alimentação e asseio. Diante disso, apreende-se Que para os sujeitos representados pelos outros entre 31 e 50 anos, cuidar de um portador de transtorno mental inclui dar uma boa alimentação e realizar a higiene pessoal do doente. No caso da modalidade cuidar, apreende-se o sentido amplo da palavra, dando características mais gerais e demonstrando Que a família tem a intenção de cuidar,no entanto, muitas vezes o Que falta é estrutura e apoio para Que este cuidar seja realizado de forma adequada.

\section{CONSIDERAÇÕES FINAIS}

Neste estudo buscou-se apreender as representações sociais construídas pela família sobre o cuidar de doentes mentais em domicilio e a partir daí explorar as representações sociais apreendidas Que influenciaram no cuidar do doente mental.

Por meio dos relatos dos sujeitos Que participaram pesquisa, foi possível, apreender como é para a família cuidar de um portador de transtorno mental em casa. Os relatos das entrevistas semiestruturadas descreveram manifestações, implicações, atitudes e crenças religiosas dos familiares, sobre o cuidar de um doente mental dentro de casa.

As manifestações sobre o cuidar do doente mental em casa apontaram para situações de dificuldades relacionadas, principalmente, com o sofrimento da família Que demonstra em seus relatos as inúmeras barreiras a serem enfrentadas para Que se possa dar uma assistência adeQuada ao ente com transtorno mental.

As implicações relacionadas ao cuidar do doente mental em casa, foram representadas pelos atores sociais, como sendo a principal causa de doenças físicas, de desestruturação da família e de solidão dos cuidadores. Isto ancora-se em fatores de relacionamento e de convivência, objetivados pela dependência, improdutividade e a atenção em tempo integral Que o doente necessita, diariamente

$\mathrm{Na}$ Questão referente as atitudes frente ao cuidar do doente mental em casa, a família representou situações ambíguas em Que encontraram-se sentimentos positivos e negativos.Desta forma, Quem teve atitudes desfavoráveis ao cuidar do doente mental apresentou o desejo de internar o paciente não para livrar-se do mesmo ou para abandoná-lo em uma instituição psiQuiátrica mas sim, como uma forma de descanso, de se refazer do cansaço e do estresse. A internação é tida como um período de "férias" para os cuidadores/familiares. 
Entretanto, a grande maioria dos familiares Que cuidam representaram Que mesmo com todas as dificuldades preferem Que o doente permaneça em casa sob seus cuidados, isto vem ancorado à falta de credibilidade Que as famílias tem das instituições e aos sentimentos amorosos Que o familiar sente pelo doente mental

A família Que cuida de um doente mental representa as crenças religiosas como o consolo para suas angustias e, como sustentação para Que tenham forças para prosseguir cuidando do portador de transtorno mental.

Durante a análise fatorial de correspondência foi possível reconhecer Que para as famílias a doença mental representa dor, despesas, agressão, dificuldades depressão, representando, assim, sentimentos despertados pela doença mental nas famílias dos doentes. Para o estímulo cuidar de um doente mental as famílias objetivaram palavras como acompanhar, agressão, asseio, dificuldade e cuidar, o
Que representa uma sobrecarga enorme para a família.

É perceptível a inter-relação existente entre as representações apreendidas na análise de conteúdo das entrevistas e as representações apreendidas na análise fatorial de correspondência através do teste de associação livre de palavras.

Os familiares representam o cuidar do doente mental no domicílio como uma alternativa de tratamento Que possibilita melhores resultados Que as internações, mas Que, no entanto, necessitam de assistência para prestar o cuidado adecuado.

É necessário, portanto, Que, baseado nos achados deste estudo, a família receba uma assistência por parte das equipes de saúde. Devem existir programas Que garantam à família do doente mental uma assistência com acompanhamento médico e pela equipe multiprofissional, para Que a carga de cuidar de um portador de transtornos mentais torne-se menos pesada.

\section{REFERÊNCIAS}

1. Soares MZS. Rompendo correntes: representações sociais sobre a reforma psiQuiátrica [dissertação]. João Pessoa (PB): Escola de Enfermagem da Universidade Federal da Paraíba; 2002.

2. Russo N. Projeto Que extingue manicômios é aprovado. Folha de São Paulo 1999 jan 22; Caderno 3:3.

3. Mello JHR. O Que é ser familiar de doente mental? Rev de Inform PsiQuiátrica 1997; 16(3).

4. Moscovi S. Prefácio. In : Jodelet D. Loucuras e representações sociais. Petrópolis (RJ): Vozes; 2005. p. 11.

5. Sá CP. Núcleo central das representações sociais. Petrópolis (RI): Vozes; 1996.

6. Ministério da Saúde (BR). Fundação Oswaldo Cruz. Diretrizes e normas regulamentadoras de pesquisa envolvendo seres humanos (Resolução 196/96 do Conselho Nacional de Saúde). Rio de Janeiro (RJ): Fiocruz; 1998.

7. Bardin L. Análise de conteúdo. Lisboa (POR): Edições 70; 1977.

8. Cibois UFR. Tri-deux mots. Versão 2.2. Paris (FRA): Sciences
Sociales; 1995.

9. Pereira H. Tratamento de Questionário: o ponto de vista da AFC. Lisboa (POR): Análise Social; 2005.

10. Doise W. Atitudes e representações sociais in : Jodelet D, organizadora. As representações sociais. Rio de laneiro (RI): UERJ; 200I.

1 1. Koga M, Fuergato AR. Convivência com a pessoa esquizofrênica: sobrecarga familiar. In: Labate RC, organizador. Caminhando para a assistência integral. Ribeirão Preto (SP): Scala; 1998.

12. Goncalves AM, Sena RR. A reforma psiQuiátrica no brasil: contextualização e reflexos sobre o cuidado com o doente mental na família. Rev Latino-Am Enfermagem 200 I; 9(2): 48-55.

13. Ackerman NW. Diagnóstico e tratamento das relações familiares. Porto Alegre (RS): Artes Médicas; 1986.

14. Jodelet D. Loucuras e representações sociais. Petrópolis (RJ): Vozes; 2005.

15. Vianna PC, Barros S. A reforma psiQuiátrica e as associações de familiares: unidade e oposição. Rev Mineira Enferm 2004; 8(2): 275-82. 